\title{
Differentiation or path dependency: a critical look at the Australian wine industry
}

\author{
David Aylward* \\ University of Wollongong, Australia
}

e In 2007 the Australian wine industry is at a crossroads, both organizationally and culturally. Having achieved considerable success over the past three decades, the industry is now operating in the shadow of that success. Ratherthan adapting to new and multiple operating pathways of a global wine landscape, industry organirations continue to steer their sector along the entrenched and restrictive pathways of previous achievement.

e This paper examines strategies that have locked the industry into a saturated, pricesensitive, commodity wine market. It explains how these strategies will inherently fail to address current challenges and opportunities, and based on empirical data, why a differentiated, region-specific approach to wine production is the most likely strategy for survival.

\section{Introduction: developmentover the past decade}

Over the past decade the Australian wine industry has undergone profound changes. Most of these changes have resulted from the industry's organizational responses to global wine trends. This paper will assess the effectiveness of these responses and their causal link with the industry's current status as a commodity wine supplier. It will also question strategies now being undertaken to address an on-going wine surplus and how more effective strategies could be implemented.

By the mid-1990s the Australian wine industry had cemented its global reputation as a

\footnotetext{
* Correspondence to: David Aylward, Research Manager, Commerce Faculty Office, University of Wollongong, NSW 2522 Australia.

E-mail: daylward@uow.edu.au
}

leader in the New World's 'new wave' of innovative wine producers. A bold vision as well as a reconfiguration of infrastructure, resources, marketing and R\&D was rapidly changing the sector's status from that of a domestic cottage industry to a respected participant in international markets. The organizational model behind this transition was one of centralization. At the hub of the new model was the Grape and Wine Research and Development Corporation (GWRDC), which was mandated with the responsibility of levy collection from producers, establishing R\&D priorities and funding those priorities from the levies and matching government dollars. Other national bodies such as the Winemakers Federation of Australia (WFA), the Australian Wine and Brandy Corporation (AWBC), the Australian Wine Export Council (AWEC) and the Cooperative Research Centre for Viticulture (CRCV) 
were also crucial participants in the new model (Aylward, 2006; Australian Wine Online, 2007; GWRDC, 2007). Together, they redefined the organizational parameters of the industry and established an innovative culture from which global growth targets could be met and exceeded.

In terms of growing both export volume and markets, the strategy was an unparalleled success. By the end of the millennium, the Australian wine industry hosted approximately 1300 producers and ranked as the world's fourth largest exporter with an income of close to $\$ 1.5$ billion per annum (Winetitles, 2001). It also dominated the popular-premium markets in both the UK and the USA, with a large number of best-selling wines being Australian. In addition, the industry's reputation grew as a 'high-tech' producer of technically faultless wine, a legacy of the Australian Wine Research Institute. Such success was reflected in imitations by other New World producers, including South Africa, Chile and Argentina. It was also reflected in the technology transfer from Australia to other producing countries in the form of direct foreign investment and 'flying winemakers', and in the acquisition desirability of Australian producers (Anderson, 2004). Rationalization of the global wine industry had begun and Australian companies were highly sought after targets.

Australia and fellow New World wine producers had successfully implemented a strategy of supplying fruit-driven, consistent and pleasant-tasting wine to a growing market of occasional drinkers. It was a market that accepted multi-region blending of the product. It was a market that was not overly concerned with a product 'story' or its heritage, as long as there was reliable quality at a reasonable price. It was also, however, a market that was being educated by producers and over time would only become more sophisticated and discerning in its product choice.

\section{Success and path dependency}

A closer appraisal of these organizational trends and developments uncovers some worrying elements. As predicted by theorists such as Hannan and Freeman (1984), paths of success often become entrenched to an extent that 'dependency' is established. Organizational behaviour follows familiar routes and patterns, rather than experimenting in alternative domains. DiMaggio and Powell (1991) are more forceful in their analysis by referring to this path dependency as the iron cage of inertia'. Their argument rests on the theory that past success creates rigid parameters (the iron cage) of behaviour that constrict alternative action to a level where forms of inertia emerge and develop. Greenwood and Hinings (1996) follow the same contention - that the behavioural environment, with its cultural and operational patterns, applies an architectural 'straightjacket' to organizations.

In such an environment, alternative architectural frameworks may expose organizations to cultural isolation and a greater risk of mortality. Regardless of the theoretical variations, it is well noted that past success within industry sectors creates a degree of risk aversion (Hannan and Freeman, 1989; DiMaggio and Powell, 1991; Ruef, 2004). As organizations and other stakeholders adhere to pathways of successful behaviour, they gain security and recognition from those pathways. Familiarity and a track record of success provide natural barriers to future divergence. Even as the external environment changes and installs new challenges and opportunities, organizations remain reluctant to alter existing behaviour (DiMaggio and Powell, 1991). Adaptability, therefore, is increasingly stifled, allowing organizational parameters to become more embedded. Eventually, a culture of inertia envelopes the operating landscape and once-successful strategies can no longer align with new, more sophisticated requirements. Such inertia also has severe consequences for most forms of differentiation, a concept that will be expanded upon later in this paper.

Within the Australian wine industry the 'dichotomous' relationship between past success and current path dependency falls clearly within the theoretical frameworks of organizational change and inertia. Particularly 
throughout the 1990s, the dominance of Australian wine in major international markets confirmed the industry's benchmarks of success, but also led to a further tightening of its operational parameters. The success in these markets was occurring in very specific price points - the popular-premium or 'commodity' sector, where the average bottle price ranged between \$US3 and \$US10. Australian exports in the super-premium and icon price points fluctuated only between slight growth and stagnation. The industry was yet to achieve the recognition for the 'fine wines' that would allow it to break into these categories.

Rather than broadening its benchmarks to incorporate other price categories and quality definitions, however, the industry remained focused almost exclusively on the commodity sector. The official position remained that this was the sector offering highest revenue growth, despite the fact that profits were already under pressure and competition was moving towards price and away from product (Eales and Binkley, 2003). By its own criteria the industry continued to achieve, and at least superficially, world markets continued to confirm this achievement. While sales from Old World producers such as France, Spain, Italy and Portugal were subject to increasing pressure in their traditional markets, New World 'innovators' such as Australia continued to expand their geographic reach and saturation (Anderson, 2004; Aylward, 2006).

Subtle warning signs began to emerge in 2002, when export volume and export value indices diverged for the first time in almost a decade. CEOs from the industry's national organizations identified the 'exponential growth' in winery numbers as the main culprit. Their claim was that the rapid influx of new and largely inexperienced vintners was the primary cause of an increasing grape supply and the consequent pressure on prices. Their argument followed that only the new, relatively inefficient producers would suffer from this over-supply and that any financial 'casualties' would be part of the industry's self-regulation (WFA, GWRDC, AWBC, 2006). Such interpretations were only partially correct and could be attributed more to an entrenched 'national-set' perspective than to an accurate reading of the situation. The problem was not that there were too many producers, but rather, that too many of these producers were sacrificing traditional, differentiated approaches to compete in the price-sensitive commodity sector.

This was in line with the strong and continuing encouragement by industry organizations to adhere to the 'Brand Australia' image (GWRDC, 2007). The multi-region production, the $\mathrm{R} \& \mathrm{D}$, the marketing and the distribution were focused on selling the world an Australian product. It was a generic branding which necessarily undermined a product, regional and, most importantly, cultural differentiation. The industry's organizational framework, as mandated under its 2025 vision, and the multinationals that dominated its landscape, demanded a national, undifferentiated framework. Industry responses to divergent export volume and value, therefore, were more closely linked to the resources and infrastructure already underpinning this national strategy than to the notion of an over-populated industry.

\section{Cultivating path dependency}

In 2007, the industry's responses remain largely unchanged. What has been added is the official statement that the international wine industry is cyclical and Australia is just one of many producers experiencing a glut. The industry expects this surplus to rebalance into equal supply and demand within several years. In fact, the past five years, from 2002 to 2007, offer a detailed case history of cultivated path dependency in the Australian wine sector. In 2007 its supply and demand equation is even more unbalanced. Export volumes are steadily increasing, while value per unit continues to decline. In March 2007, Ari Sharp reported that in the year to February export volumes leapt $11 \%$ but price per unit fell another 6\% to \$A3.69 per litre. The trend looks set to continue, with the Australian Bureau of Agricultural and Resource Economics (ABARE) 
outlook predicting $\$ A 3$ a litre by 2011 (Supply Chain Review, 2007). Further, 'more than $80 \%$ of the volume growth in Australia's wine exports is in bulk rather than bottled form'. Sharp (2007) continues his report by stating that in the USA and UK, which together account for $66 \%$ of Australian exports, the wine sells primarily at the 'cheap end of the market' ( $79 \%$ at less than $\$ A 5$ per bottle).

Data from the national survey of 100 wineries, upon which this paper is based, will show quite clearly that this situation is not the result of a cyclical over-supply of grapes. Rather, it is a consequence of the industry's reliance on a saturated, price-sensitive commodity sector to which the Australian wine industry has largely been relegated. There are, in fact, price sectors in the industry where, for more than a decade, demand has exceeded supply. Simply put, these sectors have never experienced a surplus. The survey data will show that producers operating at these higher price points remain unable to meet demand, and as a result, price per unit continues to increase. Their success can be attributed largely to differentiation. Yet throughout much of their operating history these producers have been culturally isolated in an industry that subordinates $R \& D$, resources and infrastructure to the demands of 'Brand Australia' and its servicing of the commodity sector.

The Australian wine industry today is at a critical stage in its development. It can remain dependent upon previous paths of success that no longer align with global requirements, or it can re-align to the multidimensional, differentiated operating paradigm that is revolutionizing the Bordeaux wine industry and to which New World producers such as New Zealand have successfully adapted (Barker et al., 2001; Echikson, 2004). The first option outlines the practical application of Hannan and Freeman's (1984) celebrated inertia theory. It will mean a continued dominance of policy by individuals and organizations whose operating mandate was established at a time when the industry was still in its adolescence. In organizational terms, it will mean the continued adherence to a 'national set- perspective', in which external environmental influences are peripheral rather than central to the industry's decision-making (Narula and Zanfei, 2005). And most obviously, it will mean a return to the late 1970s, when Australia's reputation was based on its ability to supply world markets with cheap, bulk wine more efficiently than any of its peers (Beeston, 1994). While such a return would forfeit the industry's capacity and potential for competitive advantage across all price points, it would indeed satisfy the requirements of a risk-averse, path-dependent environment.

The second option requires a 'global setperspective' or what organizational scholars might term an organizational ecology perspective (Trist, 1983; Astley, 1984, 1985). This allows for a recognition and acceptance of the changing global wine landscape, and a reconfiguration of operating domains, in which focus is shifted from national frameworks and priorities to the more flexible contours of region-specific production, distribution and marketing (Croser, 2004). In short, the second option requires a cultural, even anthropological embrace of the product's vitality, variety and differentiated properties (Wilson, 2004; Johnson, 2006).

\section{Why differentiation?}

In their examination of the New Zealand wine industry, Barker et al. (2001) emphasize the inextricable link between differentiation and quality, a paradigm based on product rather than price competition. They argue that in a differentiated environment, 'quality becomes (the) predominant discourse of knowledge creation' (p. 207) and further, that 'discourses of quality (are) linked to place' (p. 215). Schamel (2003) applies this same architectural analysis to the Californian wine industry, and again claims that a lesson is the clear trend towards greater regional differentiation which also suggests consumers are becoming more discerning' (p. 8). The survey findings in this paper will show that the majority of Australia's smaller wine producers also believe strongly in the benefits of regional differentiation. 
Croser (2004) applies differentiation theory to a sector analysis by claiming that the wine industry should be thought about and operationalized as two distinct sectors. He contends that there is, and should always be, a commodity sector that is largely the domain of the large corporation, capable of operating across several continents and distributing large volumes of product to mass markets. Equally, however, he argues that wine industries need to cultivate a fine wine sector that operates in parallel with the commodity sector, but delivers small quantities of highly differentiated products from highly differentiated regions to discerning markets. Perhaps Wilson (2004) captures the variable frameworks of differentiation most eloquently when he states that

\section{...the process of differentiation in which alcohol and its consumption are so impor- tant are themselves processes of globaliza- tion, in that they involve the recognition that some things, and some behaviours, set us apart from others in the world... (p. 2)}

This statement, of course, refers to a differentiation not just of the product, but of its entire cultural fabric. Differentiation ranges from the grape variety selected, to the single-vineyard planting techniques, to the harvesting methods, the vinification, the regional identification, the distribution, the marketing and finally, the consumption. It is the protection of the product's identity in every step of this supply chain that separates it and its heritage from the rest of the market (Beverland, 2005; Taplin, 2006).

\section{The Bordeaux example}

The culture of differentiation is the most obvious in the prestigious wine regions of the Old World. It is in regions such as Bordeaux that wine has become rooted in the very fabric of daily life. The region's Left Bank is populated by the centuries-old chateaux that have provided France with its fine wine identity. These include the aristocratic first growths such as Chateaux Latour, Rothschild and Haut Brion, but also the second, third, fourth and even fifth growths, to the Right Bank, where the boutique, highly specialized garage wines have generated cult followings (Echiksen, 2004). These two very distinct classes of winemaker and product can co-exist with the 20,000 other producers of fine, premium, popular and bulk wine precisely because of the region's highly differentiated framework. In terms of organization, region and operation, the wine and its makers in Bordeaux promote very distinct identities. As Kramer (2007) contends,

Realwine ... comes from continuity, from a place, from people committed to nurturing their vineyards and local wine cultures (p. 2)

The avid protection of these identities has created the strength of branding that has so far evaded New World wine industries, with the exception of New Zealand.

Across a global landscape of wine production and consumption, it is the differentiation - the contours in the landscape - that allow the industry to evolve. Without these contours, patterns of behaviour remain static, there is little expansion of organizational parameters and finally, what Hugh Johnson (2006) describes as '. . . charisma in a bottle' becomes a pleasant but bland, multi-regional product mix. By allowing multinationals to dominate policy and by following a multiregional blending strategy, the Australian wine industry is in danger of occupying an increasingly featureless reserve of the global landscape (Kramer, 2007). The 2006/7 study upon which this paper is based highlighted this danger and contrasted it sharply with the benefits of greater differentiation.

\section{Methodology}

This paper was developed in two phases. The first phase was based upon extensive literature reviews concerning: 
1. The Australian and international wine industries and discordant developments within these industries over the past decade. In particular, reviews were conducted within the context of the transition from an undersupply of wine grapes in the late 1990s to the current over-supply. Specific attention was focused on the emerging response strategies to this transition, how these strategies differ and which appear to be the more effective.

2. Organizational change, path dependency and differentiation within industry sectors. This review was concerned primarily with placing the wine industry within a context of radical change over a relatively short period of time. These changes and their responses were viewed in light of the dominant organizational change theories and underpinned the framework for the survey in phase two.

In addition to reviews, the structure of the current paper emerged from consistent findings within the author's previous studies on the wine industry. These findings provided what the author believes is a cohesive set of indicators suggesting a seismic shift in operating paradigms and a subsequent lack of organizational adaptation by industry stakeholders.

Phase two of the study was the development and implementation of a survey designed around these themes. The intention of the survey was to test the organizational change and inertia themes among boutique, small and medium-sized firms in the context of the current wine grape surplus. In parallel, the survey was designed to 'unpack' notions of differentiation and contrast the practice of this differentiation with the industry's current operating framework.

Of the 112 firms approached, a total of 100 boutique, small and medium-sized wine operators agreed to be interviewed by phone. These firms were selected using a stratified random sampling technique. Four states were covered — New South Wales, Victoria, South Australia and Western Australia - and care was taken to ensure all the major wine regions in these states were equally represented. In addition, there was careful sampling according to size, so that boutique, small and medium-sized firms were equally represented. Only exporting firms were included and in each case, either the CEO or the Marketing Manager was interviewed.

The survey questions were primarily designed for Likert-scale responses (1-5) but were also supplemented with open-ended, qualitative questions. These qualitative questions were designed to 'unpack' some of the more detailed questions concerning respondent thought on branding, regionalization, effectiveness of R\&D extension and individual operational strategies.

\section{Findings}

A key hypothesis of this paper is that differentiation allows for competition of product, rather than of price. In product competition the price sensitivity is reduced if not removed altogether. The argument follows that the more a producer is able to compete on product, the less prices are affected by a surplus of that product and, therefore, the higher the profit margin of that product (Benfratello et al., 2004; Kaniovski, 2005).

In this context, survey questions placed the concept of differentiation in contrast to the Australian wine industry's response to the current surplus. Wine producers were asked a series of questions about the effect of this surplus on their operations and strategies they had implemented as a response. The answers provided some very clear indicators of decision-making as well as a snapshot of two competing and rather contradictory strategies.

\section{The current wine surplus and its effect on operations}

Responses to this first issue set parameters for the remainder of the survey. All 100 wine producers were asked how the current surplus was affecting the viability of their operations (see Table 1). 
Table 1. Impact of wine surplus on firm operations $(n=100)$

\begin{tabular}{lc}
\hline Degree of impact on operations & Percentage \\
\hline No impact & $23 \%$ \\
Slight impact & $34 \%$ \\
Moderate impact & $24 \%$ \\
Significant impact & $12 \%$ \\
Threatening survival & $7 \%$ \\
\hline
\end{tabular}

Table 2. Association between effect of wine surplus and export status — firm categories

\begin{tabular}{llr}
\hline Impact of wine surplus & \multicolumn{1}{c}{ Export value status } & Percentage of firms \\
\hline No impact (23\%) & Export value fallen & $4 \%$ \\
& Export value unaffected & $48 \%$ \\
Slight negative impact (34\%) & Export value increased & $26 \%$ \\
& Moderate fall in export value & $21 \%$ \\
Moderately negative impact (24\%) & Export value unaffected & $65 \%$ \\
& Export value increased & $9 \%$ \\
Significant negative impact $(12 \%)$ & Significant fall in export value & $50 \%$ \\
& Export value unaffected & $25 \%$ \\
Threatens survival (7\%) & Export value increased & $16 \%$ \\
& Significant fall in export value & $67 \%$ \\
& Export value unaffected & $17 \%$ \\
& Export value increased & $0 \%$ \\
\end{tabular}

As shown in Table 1, there was a relatively even distribution across the impact categories. If responses are grouped into 'little or no impact' and 'moderate to severe impact' we see that currently $43 \%$ of survey respondents are experiencing real difficulties as a result of the wine surplus. The figure certainly indicates that at an industry level, a large percentage of boutique, small and medium-sized firms are experiencing moderate to severe problems. This hypothesis is reinforced by Pia Akerman (2007) in The Australian, who claims that the majority of Australian wineries are currently unprofitable and Chris Byrne (2006), who stated recently on the $A B C$ that as a wine producer 'we are receiving about 30-35, in some cases maybe 40 cents, in a $\$ 10$ bottle of wine?.

The issue, however, becomes more interesting when we disaggregate the impact catego- ries and use them as the basis for comparison with other variables. For example, of the $23 \%$ who stated that there was 'no impact' on their operations, only one operator claimed that their export value had fallen (by 10\%) in the past 12 months. Of the remaining, $48 \%$ claimed that export value had not been affected while $26 \%$ claimed their export value had actually increased by $10-15 \%$ in the past 12 months. Five respondents did not answer the question. For firms in this category there is a clear association between their resilience to the wine surplus and the continued success of their exports. From the following tables, the reader can see the continuity of this relationship between each category of impact and export status.

Table 2 demonstrates that for survey respondents there is a proportionate association between the negative impact of wine surplus 
Table 3. Association between impact of surplus and export price points

\begin{tabular}{|c|c|}
\hline Impact category & Average FOB price per case \\
\hline No impact & $\$ 212$ \\
\hline Slight negative impact & $\$ 114$ \\
\hline Moderate negative impact & $\$ 109$ \\
\hline Significant negative impact & $\$ 92$ \\
\hline Threatening survival & $\$ 84$ \\
\hline
\end{tabular}

on firm operations and the value of their exports. While firms that experienced no impact from the surplus demonstrated unaffected or increased export value, those firms that experienced a moderate to significant negative impact from the surplus also experienced a moderate to significant fall in the value of their exports. This relationship suggests that there is, in fact, a causal effect between impact on operations and the ability to extract export value from products.

\section{The relationship between price points, differentiation and competitive advantage}

It is a causal effect that becomes even more prominent when the export FOB prices are examined. Firms were asked to identify the average price points they targeted in export markets, with the responses being measured against the original 'categories of impact'. The results (as shown in Tables 2 and 3) confirm a clear association between resilience to the wine surplus, export value and the export price points into which the product is sold.

What is also represented in these data is the probable cause and effect between export price category - commodity, premium or icon - and resilience to an industry wine surplus. As one of the respondents, an iconic producer, typically stated when asked about the effect of the surplus:

What surplus? There is certainly no surplus at the prices points I sell at. I'm struggling to meet the demand. Business has never been better.
This was reinforced by another premium producer who insisted that

\section{We will never escape the effects of this surplus while we continue to lower our prices. There is a wine lake out there and we have to resist joining it.}

At the other end of the spectrum, those producers feeling most threatened by the surplus were responding by lowering their export prices even further. In many cases producers admitted that this was largely an act of desperation, to avoid leaving grapes on the vine, but it also highlights the extent to which the 'commodity culture' has become entrenched among lower-end producers.

The mere fact that those respondents selling at the highest price points were also the ones feeling no impact from the surplus, while those feeling most negative impact were those selling at the lowest price points, lends considerable weight to the paper's hypothesis. Further, it provides a cauterizing snapshot of the landscape that the Australian wine industry now traverses. As the respondent claimed, there is a global wine lake of blended, undifferentiated, mass-produced product. It is not dissimilar to the commodity-style markets for bread, milk or soft-drink products. Supply is exceeding demand, price competition is intense, there is little difference in product taste and for small producers, profit margins are unsustainably low. Over the past 15 years the Australian wine market has grown to a dominant position in this wine lake, but with this position has come the 'iron cage of inertia'. Parameters have become rigid and in its 
current configuration the industry has left itself little flexibility.

The 'iron cage' is particularly relevant to the smaller and medium producers. In the 1990s these producers 'piggy-backed' on the export drive of Australia's wine multinationals. They were led into a global market that was thirsty for this new, technically faultless product from the New World. The benefit to the smaller producers was immediate and significant. Within several years their markets had increased substantially in geographic spread, number and volume. They began to sell more and more of their product abroad and so eventually restructured the product and the taste to the requirements of a less discerning, less interested international customer (Croser, 2004, 2006).

It was, however, a market that multinational wine producers always had, and continued to, dominate. The smaller producers occupied a tiny proportion of this market and as more of them flooded it in their liquid 'gold rush' the supply became bloated, and accordingly, returns began to shrink. A critical marker in the fortunes of these smaller producers was the period in which their exports overtook domestic sales. Their traditional customers, who demanded and paid for a wine of distinction based on single vineyard grape selection with strong regional characteristics and handcrafted attention, were increasingly sacrificed to the bland demands of commodity-style drinkers in the UK and USA. The smaller firms were never going to match the mass plantings, distribution channels and marketing influence of their multinational 'mentors'. But unfortunately, they were beginning to match their character-free wine styles.

In 2007, the Australian wine landscape is largely without contours. It is a landscape that, while still inhabitable by Australian and international corporations, is increasingly hostile to the smaller, now undifferentiated producer. Through its R\&D extension, centralized decision-making, preference for multi-region blending and a marketing campaign of 'Brand Australia', the industry has locked itself into the commodity-style pathway. But as with the corner grocer who can no longer compete against giant super and hyper-markets, Australia's 1900 small wine producers are no longer viable participants in this commodity sector.

Like their French counterparts in Bordeaux or their New World rivals in New Zealand and the Napa and Sonoma regions of California, Australia's small producers must return to a path of greater differentiation and regionally focused identity if they are to create sustainable futures. In fact, among survey respondents $91 \%$ argued that regional differentiation of product, identity and culture was intricately linked to an enhanced reputation for wine quality. Other recent data support such a strategy. A snapshot of the Bordeaux garagistes and their product sales reveals that their smallbatch, hand-crafted products continue to sell out in futures trading (2 years before they are even bottled) at a price of up to 6000 euros a case, despite a continued global wine surplus (Echikson, 2004).

Similarly, producers from New Zealand's Marlborough region command record prices for their wine, while the New Zealand wine sector, as a whole, is the only New World industry where demand is still greater than supply. Its 1990s strategy of targeting premium and ultra-premium price points appears to be paying substantial dividends. The latest figures from California also provide strong indication that selling into the higher, differentiated price points is the optimum strategy. In April 2007, Bloomberg revealed that US exports (95\% derived from California) had 'soared 30\% in value' while only increasing $4 \%$ in volume, almost a complete reversal of Australia's March 2007 figures where exports increased only 4\% in value and $11 \%$ in volume, an effective $7 \%$ decrease in value (Mariani, 2007).

In order for this strategy of greater differentiation to develop, however, there must be an industry-led acknowledgement of the emerging and radically different operational paradigm. The Australian industry must unlock its priorities from the single-sector perspective that it has adhered to over the past three decades. It must undertake the essential reconfiguration of product manufacturing, R\&D, 
identity, branding and marketing that is now required by the dual-sector approach that other New and Old World industries are implementing so successfully.

Until now, the industry has remained reluctant to focus on a second and parallel sector, perceiving it instead as a threat to its dominance of the commodity market. To organizational scientists this reluctance is understandable and expected. The industry has built its success on a one-dimensional, onesector approach and through that success has locked itself into risk-averse strategies that will deliver 'more of the same'. This short-term security, however, is at the expense of longerterm adaptability and survival. As demonstrated by survey respondents and by isolated innovators across the Australian wine industry, there is growing demand outside the commodity wine sector and that demand has the capacity to absorb the supplies of Australia's smaller producers.

\section{Rebuilding competitive advantage}

In an environment in which the demand for $\$ 212$ cases outstrips supply, yet $\$ 84$ cases (Table 3) can no longer attract buyers, the current operating paradigm is clearly inappropriate. Producers of these $\$ 212$ cases are usually highly successful operators delivering a meticulously hand-crafted product with a distinct heritage and strong regional identity. Yet culturally, they remain isolated within what they see as a bland, nationally branded industry. For example, when asked about the importance of regional differentiation to their operations, $78 \%$ of these producers claimed it was 'significant' or 'critical', yet $74 \%$ argued that there was no recognition of, or support for, this differentiation by industry bodies.

It is argued that individual producers such as Henschke, Vasse Felix, Cullens, Petaluma and Lake's Folly rival the great wine producers of the world in terms of product quality and distinction. Yet they remain as isolated producers with little if any structural support. Their approach to the growth and production of highly differentiated products could, as with iconic producers in other wine industries, be adopted as an industry template. Within an industry that boasts one of the world's best academies (Roseworthy), a leading R\&D institute (the Australian Wine Research Institute), a heritage of innovation and an almost perfect growing climate, the potential for wines of distinction is perhaps without parallel. What are missing, however, are a cultural acceptance and a willingness to adapt. The differentiated template is certainly available but it appears that the innovative 'spirit' and adaptability which transformed the industry in the 1980s are depleted.

A rebuilding of the Australian wine industry's competitive advantage requires more than the current rhetoric about regional priorities and understanding changing consumer preferences. It requires leadership from industry bodies such as the Grape and Wine Research Development Corporation, the Australian Wine and Brandy Corporation and the Winemakers Federation of Australia. This leadership should be based on competitive advantage for each sector of the industry, not simply those sectors dominated by multinationals. Specifically, this requires four major reconfigurations.

\section{Board restructures}

The first reconfiguration relates to board membership of the national associations. Boards of major decision-making bodies such as the GWRDC, the WFA, the AWBC and the WEC have been dominated by an 'inner-circle' of policy-makers. It primarily comprises CEOs of Australia's major wine corporations, CEOs of the organizations that are in part funded by these corporations (through levies) and selected individuals whose thoughts on industry directions are considered 'appropriate'. In fact, it would be fair to say that the policies emerging from these boards over the past three decades have correlated closely with the economic interests of Australia's larger wine corporations. This has in no way been brought about through corrupt practices, but simply through economic imperatives. Since the 
funding of these organizations (and industry $\mathrm{R} \& D)$ comes in large part from a levy on grape growing and production (in tonnes crushed), it is an economic fact that most of the funding will be derived from the largest producers.

Although some attempt at democratizing these boards has taken place over the last two years, greater representation of each of the industry's sectors is required. This could be achieved by expanding board membership to include a representative from each major regional association. Not only would this diffuse the concentration of interests, but it would also instil a regionalized culture into the decision-making process. Smaller and mediumsized firms would receive greater representation through their elected board member, but possibly of equal importance, the current nationalized culture of resourcing and prioritizing would gradually give way to a regional perspective.

\section{Levy collection}

In parallel with regionally representative board structures would be a restructured levy system. As mentioned, under the current system and particularly in relation to $\mathrm{R} \& \mathrm{D}$, those who produce the most pay the most in levies and therefore, either explicitly or implicitly, exert the most influence on decision-making. Again, assessing this system from an organizational science model, the current levy structure ensures a path dependency. Alternative and innovative strategies will always be peripheral to those currently underwritten by the largest stakeholders. Change and adaptability, therefore, are only possible where benefits to the larger stakeholders are obvious. In the Australian wine industry, regional differentiation is not considered beneficial to those corporations that dominate the commodity sector. In fact, it is considered a threat.

In order to create a truly representative levy system, stakeholder voting power and R\&D extension would need to be linked to a specified production level (tonnage), rather than an individual contribution. This would allow for regional cooperatives of smaller producers to match production and, therefore, levy levels of their larger counterparts. It would ensure greater participation in the decision-making process and also more representative extension of the industry's research and development.

\section{R\&D extension to associations}

R\&D extension within the Australian wine industry is critical to a more differentiated, competitive sector. It was the national platform of R\&D in the 1980s that provided the impetus and capacity for the industry's transformation. It will be the regionalization of this R\&D in the new millennium that will allow the industry to adapt to a multidimensional landscape of production, distribution and marketing. R\&D will underpin any reconfiguration from national to regional priorities and identity. It is able to provide the innovation, the knowledge diffusion and the enhanced supply chains that individual regions will need in their efforts to differentiate.

Within the current, national $\mathrm{R} \& \mathrm{D}$ grid, priorities are set in South Australia. As the hub of the wine industry, this is where all national associations are located, where the national boards meet and consequently, where R\&D extension policy is formulated. In 2007, industry organizations are likely to argue that $R \& D$ extension has evolved considerably. They could correctly contend that a centralized R\&D model has been largely replaced by one based around regional extension programmes. Reform, in response to industry-wide pressure, is indeed taking place. Yet this new model will lack the capacity to revitalize the industry unless it is linked to robust and wellresourced regional associations. In its present form the extension programmes are still prescribed under centralized (South Australian) R\&D priorities (GWRDC, 2007).

As many respondents pointed out, the R\&D priorities of South Australia are not necessarily the R\&D priorities of their region. In fact, $66 \%$ of the survey's respondents claimed that the industry's current R\&D framework provided 'little' or 'no' value to their operations. Soil 
management, canopy management, disease and pest control, climatic responses and grape variety differ markedly from one region to the next. In short, different regions have different terroirs. The current R\&D framework simply does not account for these variations. What is required for $\mathrm{R} \& \mathrm{D}$ flexibility and responsiveness is a 'hub and spoke' model, whereby regional wine-makers and grape-grower associations link directly in terms of decisionmaking and resources to the national bodies. Resourced with R\&D field officers, proportionate funds as collected in levies from their region, mandates to differentiate their research needs and a seat on the board of the Grape and Wine Research and Development Corporation, these associations would deliver tailored R\&D extension to their own region. Such extension would not only enhance a region's innovative capacity but, again, underpin the identity and marketing of that region. It was also the type of extension that was strongly supported by survey respondents. Of those responding to this issue $(n=92)$, $87 \%$ believed that the current R\&D framework needs to be significantly more regionalized.

\section{Marketing}

Marketing of Australia's wine has developed into a contentious issue in recent years, particularly in line with the severity of the wine surplus. Smaller and medium-sized producers eager to differentiate themselves in export markets are arguing for greater sophistication of the current marketing strategy. 'Brand Australia', it is argued, gives the impression that all Australian wine comes from the 'same barrel'. This campaign, combined with the most common geographic indicator — South East Australia - confirms the industry's reputation for multi-region blending and ambiguous product heritage. The South East Australia indicator covers regions from the Upper Hunter in New South Wales, to all regions within Victoria and most in South Australia, or approximately 1400 wineries across three separate states.
A more serious issue is that 'Brand Australia' is now a 20-year-old advertising campaign. In fact, critics from Australia's major market - the $\mathrm{UK}$ - facetiously state that the image is 'tired' and could be more appropriately relabelled as 'Bland Australia' (Heijbroek, 2006; Henry, 2006). These views are reinforced by the survey's respondents; $51 \%$ claimed that the campaign was actually undermining their competitive advantage in international markets. There is a strong feeling in the Australian industry that the re-launching of 'Brand Australia' in 2006 should have incorporated specific regional identities as an extension of the national emblem. In its current format it fails to respond to sophisticated market demands or highlight Australia's diversity in region, growth and production methods, and product heritage. In short, it is advertising a single-dimension brand in a multidimensional market. Organizationally, it is also reinforcing the industry's path dependency in committing itself to production for, and supply to, a singlesector commodity market rather than adapting to the multifarious supply and demand routes now required.

\section{Concluding remarks}

Each of the above initiatives of course underlines the differentiated responses that the Australian wine industry must adopt if it is to avoid being relegated to its supply status of the 1970s. After establishing its credentials for innovative foresight throughout the 1990s, the industry allowed itself to be captured by the interests of its largest corporations. These corporations, justifiably for their own welfare, led the industry into a stable, nationalized, path dependency. It was a path dependency in which new production, $R \& D$, distribution and marketing strategies were fitted within the existing framework. The world's commodity markets had become the domain of Australian wine multinationals. Alternative routes of product identification that were emerging in Bordeaux, New Zealand and California were, and still are, perceived as a threat to this framework. 
The Australian wine industry faces further depletion unless it can extricate itself from the 'iron cage' of commodification and embrace the cultural leadership being demonstrated by its most robust regional producers. There is no threat to the commodity market. There is no threat to Australia's ability to develop young, fruit-driven, blended wine for the world's nondiscriminating drinkers. There currently exists, however, a rapidly closing window of opportunity for the industry to promote its differences, its variety, its regionality and heritage, and perhaps most importantly, its ability to produce fine wine. Only with the cultural acceptance and promotion of parallel but differentiated wine sectors can the industry move towards true maturity.

\section{Biographical note}

David Aylward is the Research Manager for the Faculty of Commerce at the University of Wollongong in New South Wales, Australia. David has been carrying out a range of innovation and internationalization-related projects with the Australian wine industry. As a result of these projects he has worked closely with a large number of industry stakeholders and has published in a number of national and international journals.

\section{References}

Akerman P. 2007. 90pc of wine trade sinking in red ink. The Australian, 19 March.

Anderson K. 2004. Introduction. In The World's Wine Markets: Globalisation at Work, Anderson K (ed.). Edward Elgar: Cheltenham; pp. 310.

Astley WG. 1984. Toward an appreciation of collective strategy. Academy of Management Review 9: 526-535.

Astley WG. 1985. The two ecologies: population and community perspectives in organizational evolution. Administrative Science Quarterly 30: 224-241.

Australian Wine Online. 2007. Australian Broadcasting Corporation, program transcript. http:// www.abc.net.au/7.30/content/2006/s1629100. htm. Broadcast: 02/05/2006. Wine industry struggles to cope with grape glut. Reporter: Mike Sexton. Australian Wine Online, Strategy 2025. http://www.winetitles.com.au/awol/ overview/strategy2025/.

Aylward D. 2006. Global pipelines: profiling successful SME exporters within the Australian wine industry. International Journal of Technology, Policy and Management 6(1): 49-65.

Barker J, Lewis N, Moran W. 2001. Regulation and development in the New Zealand wine industry. Journal of Wine Research 12(3): 199-221.

Beeston J. 1994. A Concise History of Australian Wine. Allen \& Unwin: London; pp. 4, 135, 233. Benfratello L, Piacenza M, Sacchetto S. 2004. Taste or reputation: what drives market prices in the wine industry? Estimation of a hedonic model for Italian premium wines. 2nd Annual International Industrial Organization Conference, Kellogg School of Management, Chicago, pp. 1-5.

Beverland M. 2005. Crafting brand authenticity: the case of luxury wines. Journal of Management Studies 42(5): 1003-1029.

Byrne C. Wine industry struggles to cope with grape glut. Australian Broadcasting Corporation TV program transcript, 2/5/2006, http://www. abc.net.au/7.30/content/2006/s1629100.htm.

Croser B. 2004. Brand or authenticity. Australian and New Zealand Wine Industry Journal. 1222.

Croser B. 2006. Waxing and whining. Masters of Wine Conference, Napa Valley, June.

DiMaggio P, Powell W. 1991. The iron cage revisited: institutional isomorphism and collective rationality in organizational fields. In The New Institutionalism in Organizational Analysis, DiMaggio P, Powell W (eds). The University of Chicago Press: Chicago.

Eales J, Binkley J. 2003. Vertical product differentiation in theory and practice. Journal of Agricultural and Food Industrial Organization 1(16): 1 .

Echikson W. 2004. Noble Rot: A Bordeaux Wine Revolution. WW Norton \& Co.: UK.

Greenwood R, Hinnings C. 1996. Understanding radical organizational change: bringing together the old and the new institutionalism. Academy of Management Review 21(4): 1025-1035.

GWRDC. 2007. Grape and Wine Research and Development Corporation, website accessed April, 2007. http://www.gwrdc.com.au/role.asp. 
Hannan MT, Freeman J. 1984. Structural inertia and organizational change. American Sociological Review 49: 149-160.

Hannan MT, Freeman J. 1989. Organizational Ecology. Harvard University Press: Cambridge, MA.

Heijbroek A. 2006. Time to invest in the idea of quality. Wine Business Magarine, pp. 4142.

Henry P. 2006. Industry needs creative ideas. Wine Business Monthly Sept: 26-29.

Johnson H. 2006. Wine: A Life Uncorked. Weidenfeld \& Nicolson: London; pp. 16, 35-45, 259280.

Kaniovski S. 2005. Product differentiation and competitive selection. Journal of Evolutionary Economics 15: 567-580.

Kramer M. 2007. Aussie wine cops a serve. The Age, March 27.

Mariani J. 2007. U.S. wine exports surge 30 percent in 2006, led by California. Bloomberg Press, April 2.

Narula R, Zanfei A. 2005. Globalization of innovation: the role of multinational enterprises. In The Oxford Handbook of Innovation, Fagerberg J, Mowery DC, Nelson RR (eds). Oxford University Press: Oxford; pp. 318345.

Ruef M. 2004. For whom the bell tolls: ecological perspectives on industrial decline and resur- gence. Industrial and Corporate Change 13(1): 61-89.

Schamel G. 2003. A dynamic analysis of regional and producer reputation for California wine. OENOMETRICS X, the 2003 Annual Conference of the Vineyard Data Quantification Society, Budapest, Hungary, May 22-24.

Sharp A. 2007. Wine exports up, but falling prices dent revenue. The Age Business, March 8.

Supply Chain Review. 2007. Small wineries suffer in competitive overseas market, March 12.

Taplin I. 2006. Competitive pressures and strategic repositioning in the California premium wine industry. International Journal of Wine Marketing 18(1): 61-70.

Trist EL. 1983. Referent organizations and the development of interorganizational domains. Human Relations 36: 269-284.

WFA, GWRDC, AWBC. 2006. Winemakers Federation of Australia, Grape and Wine Research Development Corporation \& Australian Wine and Brandy Corporation, interviews carried out with organization representatives as part of the study. Adelaide.

Wilson T. 2004. Globalization, differentiation and drinking cultures, an anthropological perspective. Anthropology of Food $\operatorname{Dec}(3)$ : 2-16.

Winetitles. 2001. The Australian and New Zealand Wine Industry Directory. Winetitles Publications: Adelaide. 